\title{
Mathematical Modeling and Computational Simulation of a New Biomedical Instrument Design
}

\author{
Zheng Jeremy Li \\ School of Engineering, University of Bridgeport, Bridgeport, CT 06604, USA \\ Correspondence should be addressed to Zheng Jeremy Li, zhengli@bridgeport.edu
}

Received 31 August 2012; Accepted 13 November 2012

Academic Editors: H. S. Hedia and S.-C. Ngan

Copyright () 2012 Zheng Jeremy Li. This is an open access article distributed under the Creative Commons Attribution License, which permits unrestricted use, distribution, and reproduction in any medium, provided the original work is properly cited.

Endo surgiclip instrument is the biomedical instrument that can be applied for endoscopic surgery to assist surgeons in homeostasis and secure mucosal gap surfaces during surgical operations. Since some clinic feedbacks show the surgiclip dropoff incidents which can potentially sever organ and tissue, the improvement of endo surgiclip instrument has been made in these years. Since few research papers were involved in the study of endo surgiclip instrument performance via mathematical modeling and computational simulation, currently some instrumental modifications are mainly based on clinic lab tests which prolong the improvement cycle and increase additional manufacturing cost. This paper introduces a new biomedical surgiclip instrument based on mathematical modeling, computer-aided simulation, and prototype testing. The analytic methodology proposed in this paper can help engineers in biomedical industry develop and improve biomedical instrument. Compared to the current conventional surgiclip instruments, this new surgiclip instrument can properly assist surgeon in surgical procedure with less operational force and no surgiclip drop-off incident. The prototype has also been built and tested. Both computational simulation and prototype testing show close results which validate the feasibility of this newly developed endo surgiclip instrument and the methodologies of mathematical modeling based computational simulation proposed in this paper.

\section{Introduction}

Biomedical/surgical instruments are renovated and technology-based devices requiring continuous improvement to guarantee safe use in surgery and be able to compete the challenging market [1]. The endo surgiclip instruments are commonly applied in surgical operations to repair biological defects, such as the anastomotic leakage in the gullet or gorge [2]. Recent researches indicate the flexibility and adaptability of endoscopic surgiclip instruments in curative and healing operation [3]. Endo surgiclip instruments can be applied in haemostasis using endoscopy to GI tract to repair the damaged tissues [4]. The biomedical/surgical instrument development is usually measured and controlled for its better functionality, proved feasibility, validated safety, improved reliability, and cost-effective productivity [5]. The functionality of biomedical surgiclip instruments is judged by the levels of bodily wound and tissue disturbance that biomedical devices might cause the patients [6]. The lessinvasive biomedical/surgical instruments can be developed with advances of renovated surgical technique, improved biomedical technology, better engineering materials, and well-controlled manufacturing [7]. The design and development of biomedical/surgical instrument are to combine the engineering, biomedical and surgical technologies together to implement and improve medical diagnosis, clinic treatment, and surgical operation [8]. In developing the biomedical/surgical instruments, the interdisciplinary scientific knowledge is required including mathematics, engineering, chemistry, electronics, mechanism, and physics [9]. Some recent surgical and clinic feedbacks show the surgiclip drop-off incidents due to malfunction in endo surgiclip instrument causing severe bodily disturbance, tissue trauma, and organ damage during surgery [10]. To eliminate the above defects, the current endo surgiclip instruments must be modified and improved. In this paper, the endo surgiclip instrument modification is implemented by establishing the mathematical modeling of systematic mechanism and performing computational simulation based on predefined mathematical model. To verify the analytic 


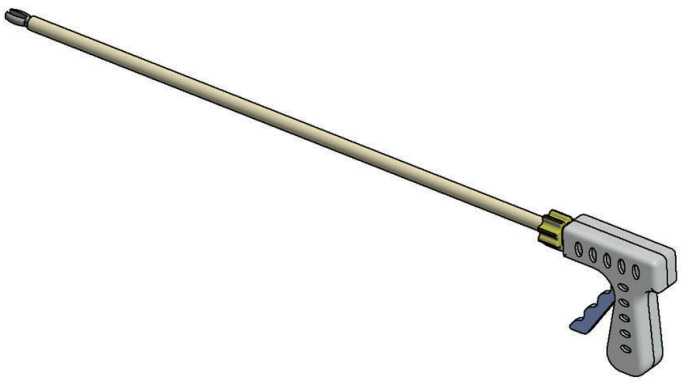

FIgURE 1: Full view of new biomedical/endo surgiclip instrument.

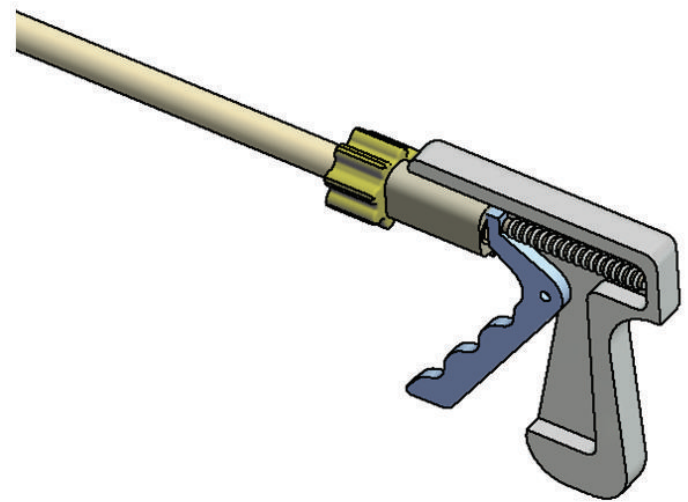

FIGURE 2: Internal mechanism view of new biomedical/endo surgiclip instrument.

solution, the prototype of this new biomedical/surgical instrument has been built and tested. Both mathematical modeling/computational simulation analysis and prototype experiment show closed results which validates the feasibility of research methodology proposed in this paper.

\section{Newly Developed Biomedical/Surgiclip Instrument}

This newly developed biomedical/surgiclip instrument, with many jointed moving parts that provide the desired instrumental motion, is shown in Figures 1 and 2.

The instrumental linkage mechanism controls the open and close function of tip jaw and spring unit keeps trigger system returning to the original position after jaw tip released. To function properly in surgical operation, $20 \mathrm{lbf}$ forces should be applied to the jaw tip through the linkage mechanism in order to completely form the surgiclip to secure the body tissues. The materials for jaw tip, pusher bar, and slider are ASTM A304L containing 1.38\% carbon content with coated Chromium to prevent these parts from carbon oxidation. One pusher bar end is jointed to the linkage mechanism and another end is connected to the jaw tip. When pusher bar at jaw tip end moves forward and passes the jaw external slop, the perpendicular force is transformed onto the jaw tip in order to form the surgiclip. To keep jaw tips normally open, an expansive spring is installed between

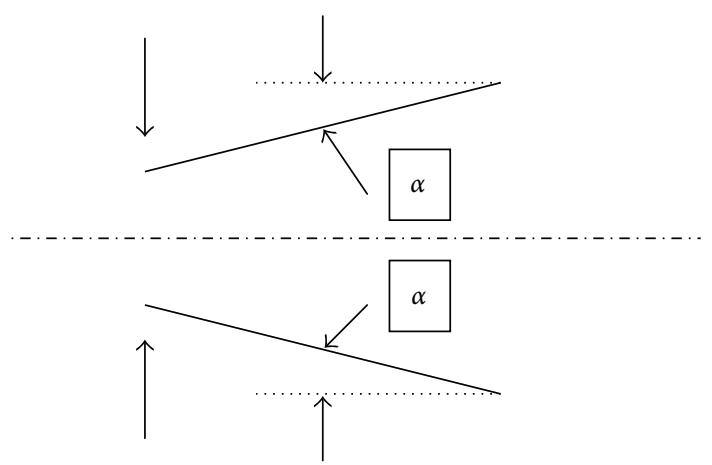

Figure 3: Jaw external geometry.

the jaw tips to keep them open when trigger handle is released.

\section{Mathematical Modeling and Computational Simulation}

Figures 3, 4, and 5 show jaw external geometry, trigger and slider linkage system, and pusher and jaw tip mechanism respectively. The force required to overcome frictional forces at points $\mathrm{O}$ and $\mathrm{Q}$ along jaw external slop is

$$
\begin{aligned}
F_{\mathrm{O}} & =\mu * N_{\mathrm{NO}} \\
& =\mu * N_{\mathrm{O}} * \cos (\alpha) \\
F_{\mathrm{Q}} & =\mu * N_{\mathrm{NQ}} \\
& =\mu * N_{\mathrm{Q}} * \cos (\alpha) \\
& =\mu * N_{\mathrm{O}} * \cos (\alpha) .
\end{aligned}
$$

Therefore the total force required is

$$
\begin{aligned}
F_{\text {total,O\&Q }} & =F_{\text {jaw closure }}+F_{\text {Oplus } \mathrm{Q}} \\
& =20 \mathrm{lbf}+F_{\text {Oplus } \mathrm{Q}} \\
& =20+2 * \mu * N_{\mathrm{O}} * \cos (\alpha)(\mathrm{lbf}) .
\end{aligned}
$$

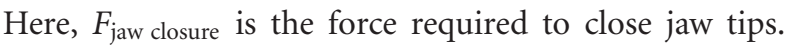
When jaw tips are fully open, the jaw external slop angle is $16^{\circ}$, shown in Figure 3.

Figure 4 displays the trigger and slider linkage system and Figure 5 shows the pusher bar and jaw tip mechanism.

The force is required to drive pusher bar as slider moves forward. Stiffness of compression spring and torsion spring are 0.465 and 0.66 , respectively.

Force required to overcome friction at point $\mathrm{H}$ is

$$
\begin{aligned}
F_{\mathrm{H}} & =\mu * N_{\mathrm{NH}} \\
& =\mu * N_{\mathrm{H}} * \cos (\beta)(\mathrm{lbf}) .
\end{aligned}
$$

Force required to overcome friction at point $\mathrm{R}$ is

$$
\begin{aligned}
F_{\mathrm{R}} & =\mu * N_{\mathrm{NR}} \\
& =\mu * N_{\mathrm{R}} * \cos (\beta)(\mathrm{lbf}) .
\end{aligned}
$$




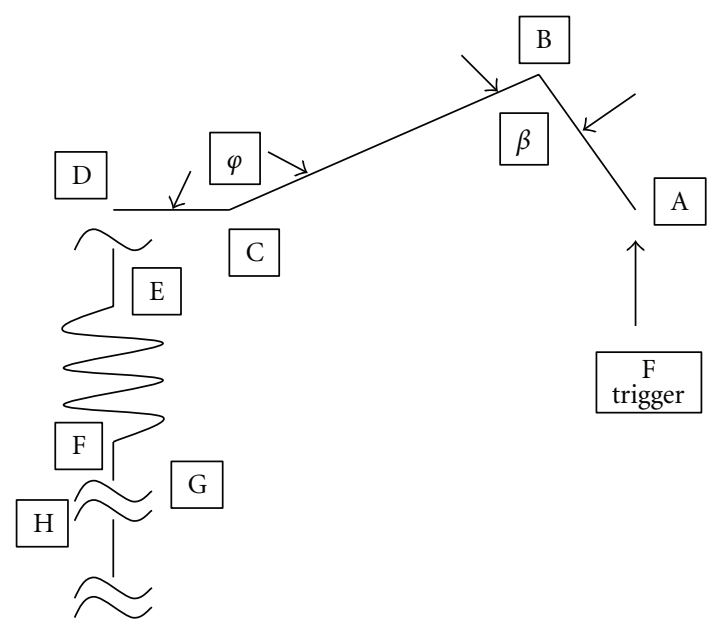

FIgURE 4: Trigger and slider linkage system.

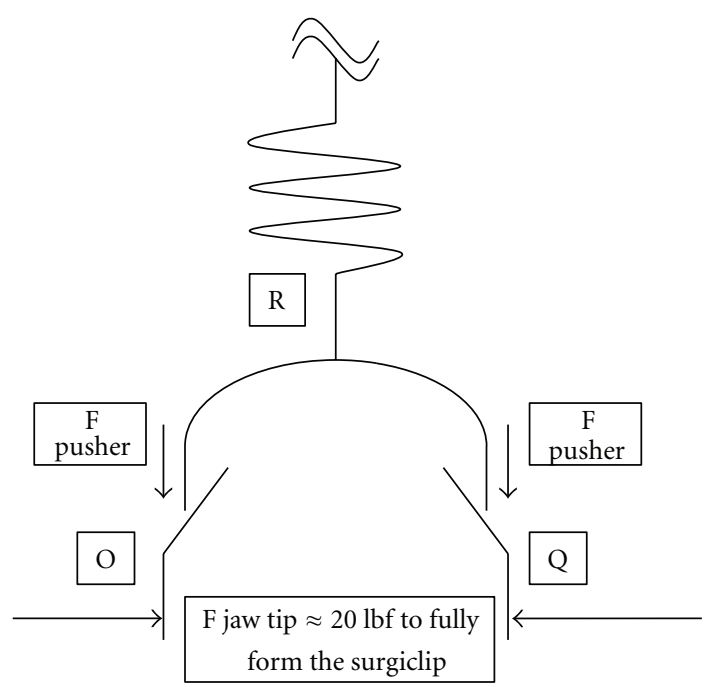

FIgURe 5: Pusher and jaw tip mechanism.

Total force required to overcome friction at points $\mathrm{H}$ and $\mathrm{R}$ is

$$
\begin{aligned}
F_{\text {total, } \mathrm{H} \& \mathrm{R}} & =\mu *\left(N_{\mathrm{NH}}+N_{\mathrm{NR}}\right) \\
& =\mu *\left(N_{\mathrm{H}}+N_{\mathrm{R}}\right) * \cos (\beta)(\mathrm{lbf}) .
\end{aligned}
$$

Force required to overcome friction at point $\mathrm{G}$ is

$$
\begin{aligned}
F_{\mathrm{G}} & =\mu * N_{\mathrm{NG}} \\
& =\mu * N_{\mathrm{G}} * \cos (\varphi)(\mathrm{lbf}) .
\end{aligned}
$$

Force required to overcome friction at point I is

$$
\begin{aligned}
F_{\mathrm{I}} & =\mu * F_{\mathrm{NI}} \\
& =\mu * N_{\mathrm{I}} * \cos (\varphi)(\mathrm{lbf}) .
\end{aligned}
$$

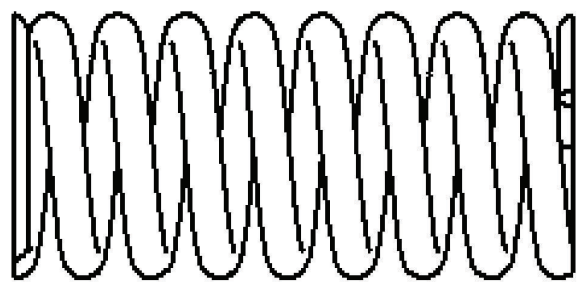

FIgURE 6: Compression spring in this new biomedical instrument. I is

Total force required to overcome friction at points $G$ and

$$
\begin{aligned}
F_{\text {total, }, \mathrm{G} \& \mathrm{I}} & =\mu *\left(N_{\mathrm{NG}}+N_{\mathrm{NI}}\right) \\
& =\mu *\left(N_{\mathrm{G}}+N_{\mathrm{I}}\right) * \cos (\varphi)(\mathrm{lbf}) .
\end{aligned}
$$

So the total force required to overcome frictions from points $\mathrm{O}, \mathrm{Q}, \mathrm{H}, \mathrm{R}, \mathrm{G}$, and $\mathrm{I}$ is

$$
\begin{aligned}
& F_{\text {total, O-Q-H-R-G-I }} \\
&=\mu *\left(20+F_{\text {Oplus } \mathrm{Q}}+N_{\mathrm{NH}}+N_{\mathrm{NR}}+N_{\mathrm{NG}}+N_{\mathrm{NI}}\right) \\
&=\mu *\left\{20+2 *\left[N_{\mathrm{O}} * \cos (\alpha)\right]\right. \\
&+\left[\left(N_{\mathrm{H}}+N_{\mathrm{R}}\right) * \cos (\beta)\right] \\
&\left.+\left[\left(N_{\mathrm{G}}+N_{\mathrm{I}}\right) * \cos (\varphi)\right]\right\} .
\end{aligned}
$$

The force angles at contact points $\mathrm{O}$ and $\mathrm{Q}$ change along jaw external slop and force angles at contact points $H, R, G$, and I varies with different trigger closure angle. The force required to handle the trigger is

$$
\begin{aligned}
& F_{\text {Handle }} \\
& =F_{\text {compression spring }}+F_{\text {torsion spring }}+F_{\text {total, }} \text {-Q-H-R-G-I } \\
& =F_{\text {compression spring }}+F_{\text {torsion spring }} \\
& +\mu *\left\{20+2 *\left[N_{\mathrm{O}} * \cos (\alpha)\right]\right. \\
& +\left[\left(N_{\mathrm{H}}+N_{\mathrm{R}}\right) * \cos (\beta)\right] \\
& \left.+\left[\left(N_{\mathrm{G}}+N_{\mathrm{I}}\right) * \cos (\varphi)\right]\right\} .
\end{aligned}
$$

For compression spring shown in Figure 6, the compression spring rate is

$$
\begin{aligned}
K_{\mathrm{CP}} & =\frac{\text { load }}{\text { displacement }} \\
& =\frac{F_{\text {load }}}{S_{\text {displacement }}},
\end{aligned}
$$

and the maximum shear force in compression spring is

$$
F_{\text {max shear }}=\frac{8 * F_{\text {load }} * D_{\mathrm{OD}} * K_{\mathrm{CP}}}{3,1416 * d_{\mathrm{ID}}} .
$$

The torsion spring, installed at the back of trigger handle, can be applied to move trigger back to its original position 


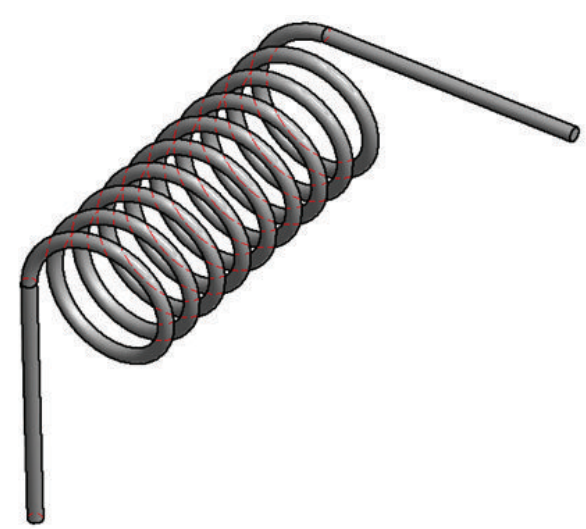

FIGURE 7: Torsion spring in this new biomedical instrument.

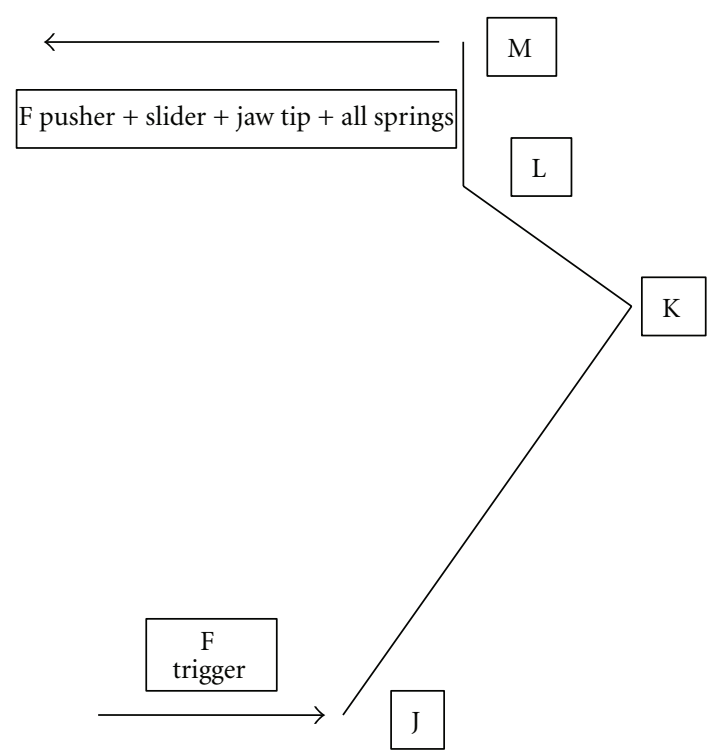

Figure 8: Force diagram of trigger handle.

after trigger is released. For torsion spring displayed in Figure 7, the force loaded on torsion spring is

$$
F_{\text {loaded }}=\frac{K_{\text {torsion-spring }} * \xi_{\text {deflection }}}{M_{\text {moment-arm }}} .
$$

The above complex calculation of forces in (11) at different force angles can be performed through computational simulation based on predefined mathematical models.

The trigger design needs considering handle body strength to keep better instrumental function, ergonomic contour features to prevent surgeon hands from fatigue, and less operational force to ease surgeon in surgical operation.

Figure 8 displays the force diagram and Figure 9 shows the geometric diagrams of trigger in its start (jaw tips fully open) and end (jaw tips fully closed) positions. Based on Figure 9, the distance of L-J in vertical direction is

$$
L_{\mathrm{L}-\mathrm{J}, \text { vertical }}=\mathrm{LK} * \sin (\omega)+\mathrm{KJ} * \sin (\gamma) .
$$

As the surgeon applies force to the instrument trigger, the other end of trigger handle will drive the instrumental

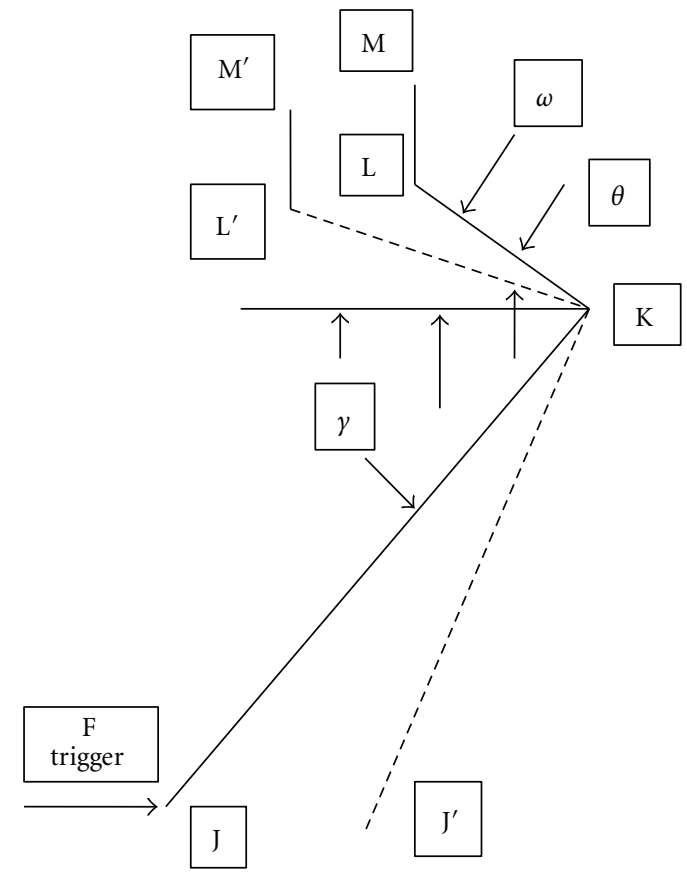

FIGURE 9: Geometric diagram of trigger motion.

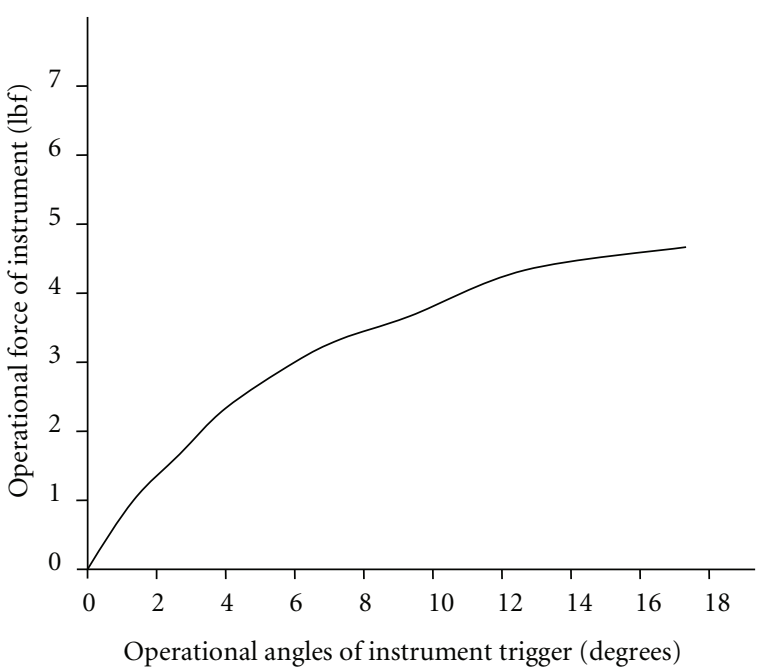

FIGURE 10: Instrumental operation force versus trigger angles.

pusher bar forward to load surgiclip into jaw tip track. The pusher bar stays inside jaw tip but a small front portion of surgiclip moves outside jaw tip before reaching the tissue target. The surgiclip will further move and secure body tissue as the surgeon continuously operates the instrument.

Based on the above mathematical modeling (11)-(15), the instrumental operation force can be determined through computational simulation and the analytic result is shown in Figure 10.

The computational simulation indicates that the maximum operation force of this new biomedical instrument to fully form the surgiclip is $3.725 \mathrm{lbf}$ which is lower than $4 \mathrm{lbf}$ operation force in current traditional surgiclip instruments 
TABLE 1: Experimental force results in this new biomedical instrument.

\begin{tabular}{lc}
\hline $\begin{array}{l}\text { Experiment } \\
\text { number }\end{array}$ & $\begin{array}{c}\text { Operation force in new biomedical instrument } \\
(\text { lbf })\end{array}$ \\
\hline 1 & 3.722 \\
2 & 3.727 \\
3 & 3.721 \\
4 & 3.729 \\
5 & 3.732 \\
6 & 3.721 \\
7 & 3.735 \\
8 & 3.723 \\
9 & 3.721 \\
10 & 3.735 \\
\hline Average & 3.7267 \\
\hline
\end{tabular}

due to improved driving mechanism in this new instrument design. This improvement will benefit the surgeons in their surgical operations and clinic treatment applications.

The computer-aided simulation is applied to perform optimal design on this endosurgical instrument. The combinations of different linkage angles and length ratio are introduced in the computational simulation to determine the above combination of linkage angle and length ratio that is best for this biomedical instrument design.

\section{Prototype Testing of this New Biomedical Instrument}

The prototype of this new biomedical instrument has been built and tested to verify the mathematical modeling based computational simulation. The experimental result is shown in Table 1.

The experimental results of this new biomedical instrument show the average maximum operational force to fully form the surgiclip is $3.7267 \mathrm{lbf}$ which is very close to the maximum operational force of $3.725 \mathrm{lbf}$ by mathematical modeling based computational simulation. This validates the credibility of the mathematical modeling proposed in this paper. Also, the prototype testing indicates that no surgiclip drop-off incident during testing due to improved instrument mechanism design.

\section{Future Improvement on this New Biomedical Instrument}

The future improvement will include further simplifying the instrument design to lower manufacturing cost, investigate possible design solution to further decrease instrument operation force, reduce linkage numbers to bring down friction loss, and modify body/trigger ergonomic contour to further trim down the risk of hand fatigue. The prototype of further modified instrument will be built and tested in the lab and will also be sent to the clinic field for further evaluation thereafter.

\section{Conclusion}

The improvement of biomedical instruments can efficiently help doctors and surgeons in the medical treatment and surgical procedure. This new biomedical/surgical instrument is designed to prevent endo surgical instrument from surgiclip drop-off incident to avoid severe body tissue injury in surgical procedure and prototype experiment indicates no surgiclip drop-off incident in medical treatment. The mathematical modeling based computational simulation shows lower operational force required in this new instrument design if compared to the current existing surgiclip instruments and this improvement can ease surgeon in their future surgical operation. Both mathematical modeling based computational simulation and prototype experiment show very close results which validates the credibility of analytic methodology proposed in this paper.

\section{References}

[1] R. Lu, C. Curcio, Y. Zhang et al., "Investigation of the hyperreflective inner/outer segment band in optical coherence tomography of living frog retina," Journal of Biomedical Optics, vol. 17, pp. 38-48, 2012.

[2] D. R. Masys, G. P. Jarvik, N. F. Abernethy et al., "Technical desiderata for the integration of genomic data into Electronic Health Records," Journal of Biomedical Informatics, vol. 45, no. 3, pp. 419-422, 2012.

[3] A. Uchugonova, M. Lessel, S. Nietzsche, H. Zeitz, K. Jacobs, and C. Lemke, "Nanosurgery of cells and chromosomes using near-infrared twelve-femtosecond laser pulses," Journal of Biomedical Optics, vol. 17, pp. 88-95, 2012.

[4] T. G. Kannampallil, G. F. Schauer, T. Cohen, and V. L. Patel, "Considering complexity in healthcare systems," Journal of Biomedical Informatics, vol. 44, pp. 943-947, 2011.

[5] A. Wright, E. S. Chen, and F. L. Maloney, "An automated technique for identifying associations between medications, laboratory results and problems," Journal of Biomedical Informatics, vol. 43, no. 6, pp. 891-901, 2010.

[6] S. X. Liu, "Symmetry and asymmetry analysis and its implications to computer-aided diagnosis: a review of the literature," Journal of Biomedical Informatics, vol. 42, no. 6, pp. 10561064, 2009.

[7] T. Bevan, R. Carriveau, L. Goneau, P. Cadieux, and H. Razvi, "Numerical simulation of peristaltic urine flow in a stented ureter," American Journal of Biomedical Science, vol. 4, pp. 238244, 2012.

[8] W.-P. Cheng, G.-J. Wu, B.-W. Wang, and K.-G. Shyu, "Regulation of PUMA induced by mechanical stress in rat cardiomyocytes," Journal of Biomedical Science, vol. 19, no. 1, pp. 38-45, 2012.

[9] A. Subramanian, U. M. Krishnan, and S. Sethuraman, "Development of biomaterial scaffold for nerve tissue engineering: biomaterial mediated neural regeneration," Journal of Biomedical Science, vol. 16, pp. 108-112, 2009.

[10] X. Kan, C. Li, H. Zhou et al., "Three dimensional ordered macroporous electrochemical sensor for dopamine recognition and detection," American Journal of Biomedical Science, vol. 4, pp. 184-193, 2012. 


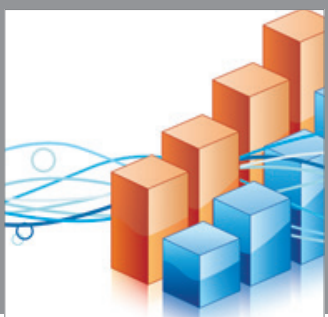

Advances in

Operations Research

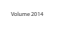

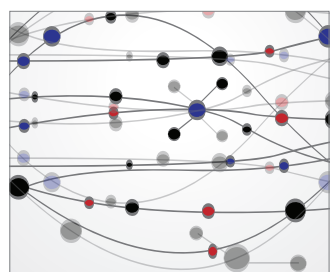

\section{The Scientific} World Journal
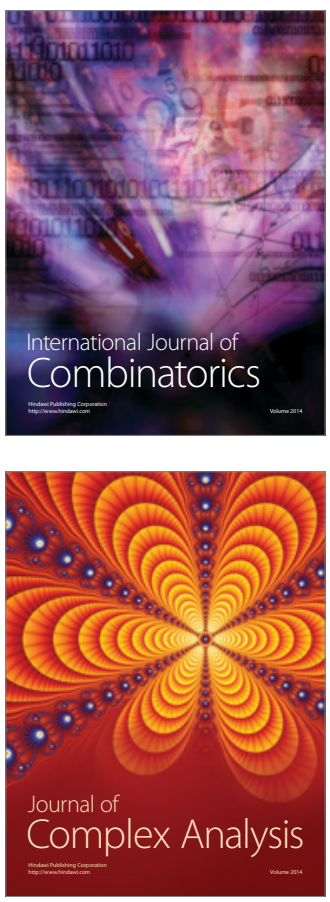

International Journal of

Mathematics and

Mathematical

Sciences
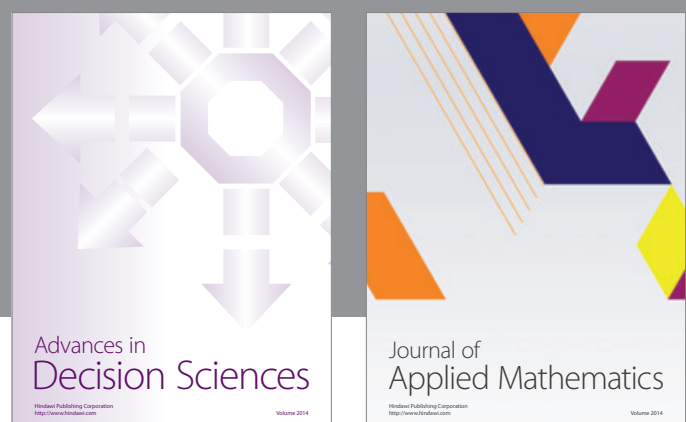

Journal of

Applied Mathematics
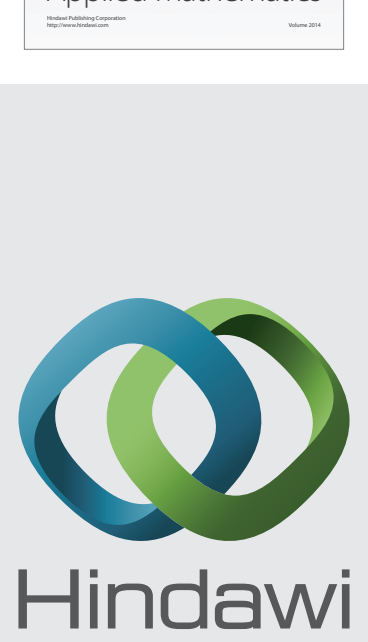

Submit your manuscripts at http://www.hindawi.com
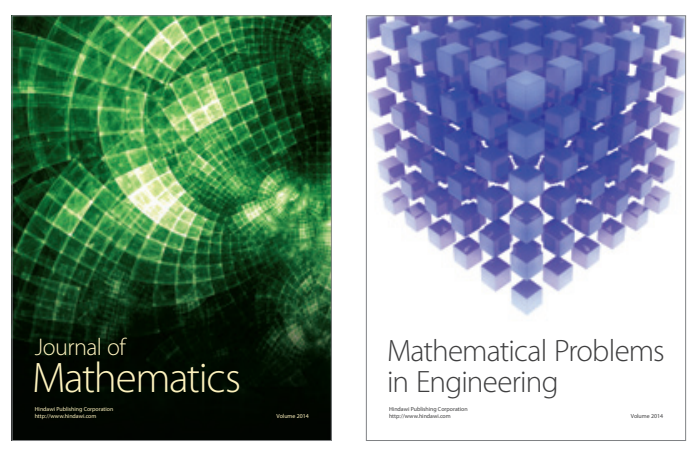

Mathematical Problems in Engineering
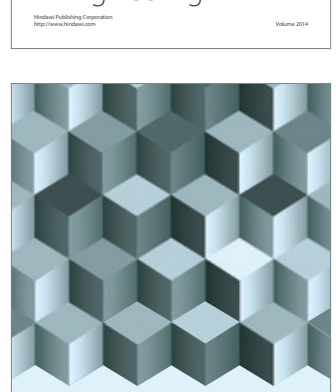

Journal of

Function Spaces
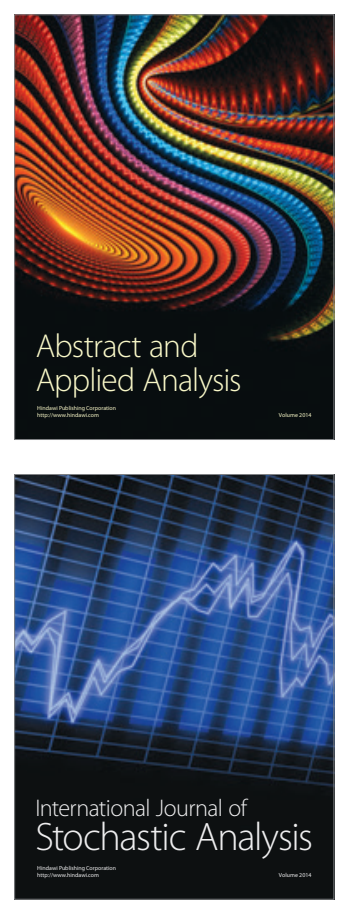

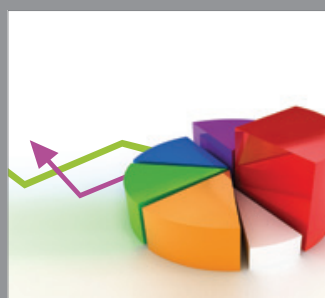

ournal of

Probability and Statistics

Promensencen
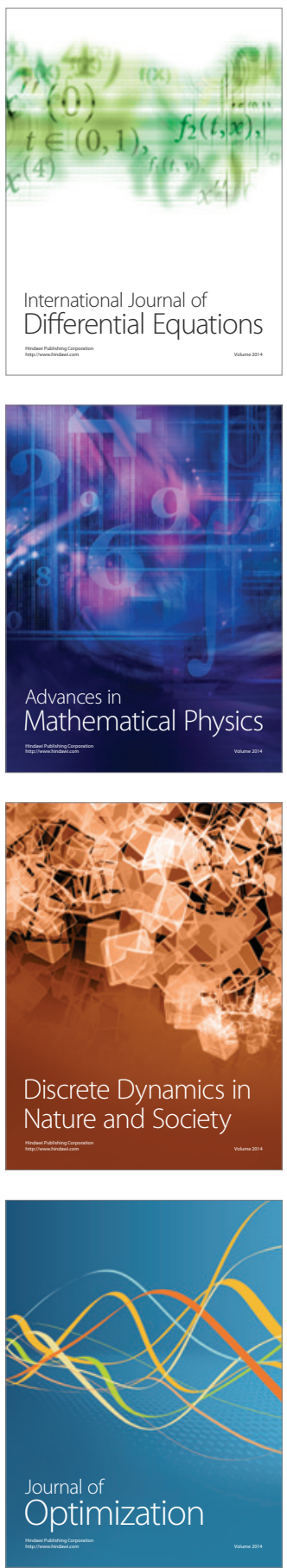